\title{
Servicios de extensionismo tecnológico para el desarrollo de las industrias culturales y creativas
}

Technological Extension Services for the Development of Cultural and Creative Industries

Santiago Alfaro Rotondo Pontificia Universidad Católica del Perú

Resumen: Los servicios de extensionismo tecnológico (SET) forman parte de políticas industriales y de innovación implementadas en diferentes países de Iberoamérica para impulsar la sostenibilidad de las industrias culturales y creativas. En base a una investigación cualitativa sobre la situación actual de este tipo de servicios en el Perú, el artículo propone priorizar cinco de ellos para promover los negocios culturales en economías emergentes como la peruana. Se sostiene que los bienes y servicios culturales tienen características económicas particulares, como la centralidad de la creatividad en los procesos productivos y la demanda impredecible. En consecuencia, el artículo explica que, para desarrollarlos mediante el extensionismo tecnológico y sus indicadores de desempeño, se requiere aplicar criterios distintos a los usados en las industrias extractivas o la manufactura. 
Palabras clave: industrias culturales y creativas, servicios de extensionismo tecnológico, innovación blanda, desarrollo de públicos, Perú.

Abstract: Technological extension services (TES) are part of industrial and innovation policies implemented in different Latin American countries to promote the sustainability of cultural and creative industries. Based on a qualitative research about the current situation of this type of services in Peru, the article proposes to prioritize five of them to promote cultural businesses in emerging economies such as the Peruvian one. I argue that cultural goods and services have particular economic characteristics such as the centrality of creativity in productive processes and the unpredictable demand. Consequently, the article explains that, in order to develop them through technological extensionism and their performance indicators, it is necessary to apply different criteria from those used in the extractive or manufacturing industries.

Keywords: cultural and creative industries, technological extension services, soft innovation, audience development, Peru.

Fecha de recepción: 3/6/2021

Fecha de aceptación: 9/8/2021 
Las industrias culturales y creativas (ICC, en adelante) han sido promovidas por los Estados principalmente a través de políticas e instituciones culturales. En las últimas dos décadas, sin embargo, debido al incremento de su aporte a la economía y al aumento de la conciencia pública sobre ello, otras entidades del Estado dedicadas al fomento y promoción empresarial han venido implementando políticas industriales para desarrollarlas, tanto a nivel nacional como local. Los servicios de extensionismo tecnológico (SET, en adelante) forman parte de ese tipo de políticas llevadas a cabo en la región por organismos como la Corporación de Fomento de la Producción (CORFO) de Chile o el Ministerio de Educación e Innovación del Gobierno de la Ciudad de Buenos Aires.

En el presente artículo se proponen servicios de extensionismo tecnológico para las industrias culturales y creativas de economías emergentes; a partir de la actualización de los resultados de un estudio realizado por encargo del Instituto Tecnológico del Perú (ITP), organismo técnico especializado del Ministerio de la Producción. La investigación original tuvo como objetivo central el de desarrollar un diagnóstico de la situación actual de ese tipo de servicios en el Perú, a fin de obtener insumos para el diseño de un centro de extensionismo. Con el interés de alcanzarlo, el levantamiento de información se realizó mediante el uso de metodologías mixtas: el análisis de fuentes secundarias, recolección de indicadores cuantitativos y la construcción de información cualitativa, realizada a través de la aplicación de entrevistas y grupos focales $(n=46)$.

De todo lo recogido, aquí solo se da cuenta del tipo de servicios más requeridos por los entrevistados: artistas, investiga- 
dores y gestores culturales de la música, el diseño de modas y la actividad audiovisual (videojuegos, animación y cinematografía) de cuatro regiones peruanas (Lima, Arequipa, Puno y Piura). Asimismo, también se explican las particularidades de los procesos de innovación en las ICC, derivadas de la especial naturaleza de los bienes, servicios y actividades culturales, ya que los servicios de extensionismo tecnológico requieren ser diseñados basándose en ellas. En el ecosistema de la cultura y la creatividad

Los servicios de extensionismo tecnológico son un tipo de «asistencia provista directamente a empresas para estimular la modernización y mejora tecnológica, con foco en pequeñas y medianas empresas» (Shapira et al., 2015: 2). También pueden ser definidos como «la actividad a través de la cual se logra que las firmas accedan e incorporen procedimientos, técnicas y conocimientos nuevos en sus procesos productivos y de negocios» (Sierra, 2010). Su uso es común en las políticas industriales y de innovación. No obstante, las reglas que rigen otras actividades económicas no son iguales a las del ecosistema cultural. Por esa razón, implementarlos como un instrumento de desarrollo de las ICC exige un ejercicio de adecuación a sus dinámicas, tal como se argumenta a continuación.

\section{La economia de las industrias culturales y creativas: excepción a la regla}

La cadena de valor de las ICC varía en cada uno de los sectores que las componen. Sin embargo, hay patrones similares, actualmente en proceso de cambio por la expansión de las tecnologías digitales y la globalización. El punto de partida común es la creación de un producto cultural que, al momento de ser comercializado, adquiere un valor cultural y un valor económico, convirtiéndose en una forma de capital o de mercancía cultural. El valor cultural tiene sus orígenes en el reconocimiento social 
y el valor económico en las dinámicas de oferta y demanda del mercado (Rama, 2003: 46-47).

Los productos culturales son «bienes o servicios ofrecidos por una unidad institucional a otra y que tienen un valor económico» (Convenio Andrés Bello, 2009: 59). Desde la creación hasta su apropiación por parte de un consumidor, los productos culturales recorren la siguiente cadena:
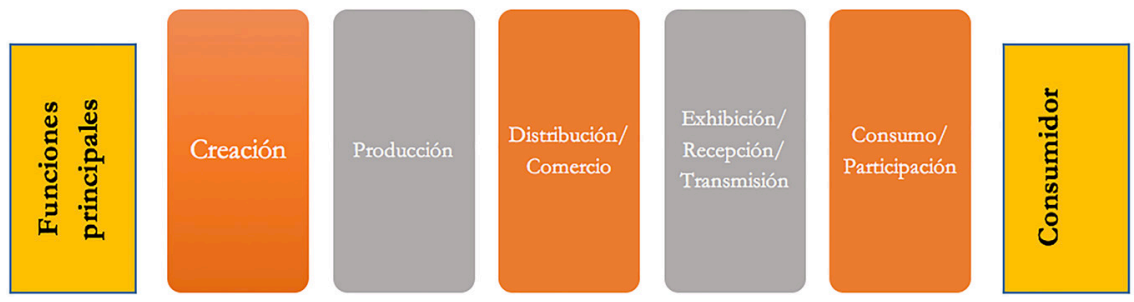

Figura 1. Cadena de valor de las industrias culturales y creativas.

Fuente: elaboración propia basada en Unesco (2009).

Adicionalmente a estas cinco actividades, el departamento estadístico de la Unesco identifica otras tres de tipo transversal que no son parte de la cadena de valor pero que cumple un importante rol en ella (Unesco, 2009):

- La formación y educación.

- La preservación y archivo.

- Equipamiento y materiales de soporte.

En algunos sectores como el audiovisual, la producción puede ser desglosada en dos eslabones: la preproducción (identificación de locaciones, maquillaje, gestión de derechos de autor, etc.) y la posproducción (efectos especiales, doblaje, sonorización, etc.). Por su lado, en la industria editorial, la producción se divide en edición e impresión. Los eslabones de la cadena de valor de las ICC no pueden ser, en consecuencia, estandarizados. 
Lo mismo pasa, incluso, con el universo de actividades económicas cobijadas bajo la categoría de «industrias culturales y creativas». Como lo han demostrado estudios de investigadores como Peter Campbell, Dave O’Brien y Mark Taylor, las industrias creativas (software, telecomunicaciones, servicios computacionales, diseño, publicidad), ligadas a actividades tecnológicas y funcionales, aportan más a la economía que las industrias culturales (industria editorial, audiovisual o musical) y poseen trabajadores con patrones propios de consumo cultural. Resulta necesario, entonces, desagregar las industrias «culturales» de las «creativas» para poder comprenderlas y promoverlas (Campbell et al., 2018).

En todo caso, más allá de las diferencias que poseen, en general, la expansión de las tecnologías digitales ha tenido efectos multidimensionales en la estructura económica de su cadenas de valor. Entre esos efectos, está el hecho que las actividades vinculadas a los servicios han adquirido mayor protagonismo sobre la producción de bienes, el surgimiento de nuevos mecanismos de conocimiento de la actividad de los consumidores (a través de la inteligencia artificial), la intervención de los públicos en la creación (al emerger la figura del «prosumidor» mediante procesos de cocreación como el crowsoursing), la emergencia de nuevos modelos de negocio (como la venta del acceso a productos vía streaming) o la transformación del balance de poder entre los agentes: algunos intermediarios han adquirido mucho poder (Google, Amazon, Facebook, Apple), otros han perdido el que tenían como sucedió con las empresas discográficas en el campo de la música (Mangematin, Sapsed y Schüßler, 2014; Towse, 2016; Yúdice, 2018).

Los cambios, sin embargo, no han alterado las características económicas particulares de las industrias culturales y creativas, manifestadas especialmente en la de tipo «cultural». Entre ellas, las más destacadas por la literatura especializada en el tema son (Garnham, 2011: 29-30; Convenio Andrés Bello, 2009: 39; Zallo, 
2007; Miège, 2011): la comunicación de significados a través de imágenes, materiales físicos, sonidos y/o palabras; la posesión de economías de escala donde los costos de producción son altos y los de distribución muy bajos; la generación de productos con la capacidad potencial de ser protegidos jurídicamente por alguna forma de propiedad intelectual, como los derechos de autor, copyright o licencias copyleft, y su inserción en circuitos comerciales donde prima, en mayor o menor medida, la división social del trabajo.

Junto con esta lista, las investigaciones sobre la economía de las ICC suelen resaltar otras dos características del comercio de bienes y servicios culturales y creativos, ambas claves para comprender sus dinámicas específicas de innovación y, en consecuencia, también para diseñar servicios de extensionismo tecnológico ajustados a su realidad.

\section{A) La creatividad como componente central de la producción}

Los procesos de producción de las ICC no son iguales a los de la industria automovilística o las industrias extractivas. En ellos, el componente estético y creativo de los productos es más importante que su funcionalidad (Nesta, 2009). A su vez, los productos son siempre nuevos, no están estandarizados como las latas de atún o las licuadoras. De ello se derivan una serie de consecuencias. La remuneración por el trabajo de los creadores (autores o intérpretes), por ejemplo, se realiza a través del sistema salarial pero también a través de otros como el sistema de derechos de autor. En muchos casos, incluso, dicha remuneración solo opera a través de este último sistema. Ese es el caso del pago a los autores de libros, quienes suelen recibir únicamente regalías como compensación a su trabajo.

El carácter colectivo de la creación y su desarrollo a través de proyectos también forma parte de las características cen- 
trales de los procesos de producción de las ICC. Una obra cinematográfica o de ficción televisiva, por dar dos casos, son productos del trabajo intelectual del director, guionista, actores y otros agentes. La gestión de los derechos de propiedad sobre este tipo de creaciones tiende a motivar negociaciones de los derechos de explotación comercial de la obra a favor de los productores. Por esa razón, con consecuencias muchas veces nocivas para ellos, a los artistas de producciones audiovisuales como las series televisivas se les paga una alta remuneración mensual a cambio de renunciar a sus derechos patrimoniales sobre el producto final mediante el uso de la modalidad de trabajo bajo contrato (work for hire) u obra por encargo. Eso explica que a los actores de la telenovela colombiana Betty la fea no se les haya pagado las regalías por su transmisión en 180 países $^{1}$.

Al peso del sistema de derechos de autor en la remuneración y al carácter colectivo de la creación, se suma la temporalidad de los procesos creativos. Las obras son creadas mediante proyectos efímeros, por lo que las empresas suelen tener trabajadores eventuales antes que fijos y el mercado laboral está dominado por trabajadores independientes. En el teatro, actores y técnicos conforman equipos para ensayar e interpretar una obra para luego separarse y conformar otros equipos. Lo mismo pasa en la música, el cine o la animación. El trabajo en las ICC, en consecuencia, tiende a ser bastante inestable y precario, lo que ha llevado a desarrollar legislaciones laborales específicas que abordan la intermitencia del trabajador del arte a través del reconocimiento de derechos y regulaciones especiales como sucede con el Estatuto del artista de España o el régimen de los intermitentes del espectáculo de Francia.

$1 \mathrm{Al}$ respecto, ver: https://www.eluniverso.com/entretenimiento/television/las-regalias-debetty-la-fea-que-el-elenco-de-la-novela-nunca-ha-recibido-nota. 


\section{B) La aleatoriedad de la demanda}

La segunda característica particular de la economía de la ICC está relacionada con el hecho de que las elecciones realizadas por los consumidores culturales no dependen de apreciaciones objetivas ni puede ser anticipada (Tolila, 2007). La calidad es evaluada a partir de criterios subjetivos, por lo que no puede ser medida, esto es, sometida a reconocimiento general como podría ser la mayor potencia de un automóvil sobre otro. Asimismo, los consumidores no discriminan entre grupos de música o directores de cine como lo hacen entre electrodomésticos. Las canciones y películas son «bienes de experiencia», hasta no ser escuchadas o vistas no puede determinarse la satisfacción que motivarán o, como lo señala la taxonomía económica, cuánta utilidad generarán.

La imposibilidad de clasificar y jerarquizar contenidos artísticos y de prever su utilidad, vuelve a la demanda aleatoria. Los grandes éxitos comerciales son difíciles de anticipar. Como consecuencia, la inversión en las industrias culturales y creativas resulta altamente riesgosa. Los productores tienden a optar por estrategias como fortalecer el sistema de estrellas, donde «un número relativamente pequeño de personas gana enormes cantidades de dinero y parece dominar los campos a los que se dedican» (Rosen, 1981); o promover la sobreproducción a través de la inversión en muchos tipos de productos, ya que pocos éxitos financian muchos fracasos (Jenkins et al., 2015: 223; Tolila 2007).

A la vez, al ser los culturales «bienes de experiencia», la incertidumbre también se traslada al lado de los consumidores, quienes requieren de conocimientos e información para orientarse en los mercados culturales. El consumidor no puede anticipar si una obra les generará satisfacción antes de experimentarla aunque sea producida por sus artistas favoritos (Richeri, 2011: 149). El periodismo cultural contribuye a reducir esa incertidumbre 
en el público, aunque actualmente los comentarios de conocidos o los que circulan en redes sociales sean más influyentes.

Sumado a ello, el consumo cultural se desarrolla por medio de procesos de adicción racional (Stigler y Becker, 1977). Es decir, es un tipo de consumo que las experiencias pasadas no motivan saturación (como al comer muchos dulces) sino, por el contrario, incentivan los consumos futuros. Las preferencias de los consumidores en el campo cultural se forman a través de la acumulación de experiencias y al generar un stock de conocimientos, un capital cultural. Por eso, la educación artística, la adquisición de competencias y capacidades para percibir y apreciar los bienes y servicios culturales, son determinantes en las dinámicas de la demanda cultural.

\section{La innovación en las industrias culturales y creativas}

Se entiende por innovación a la transformación de nuevas ideas en soluciones económicas y sociales (Navarro, Benavente y Crespi, 2016). Para comprender su rol en las ICC, teniendo en cuenta la centralidad de la creatividad y de la aleatoriedad de la demanda, resulta necesario adoptar un enfoque «demarcatorio» que ponga énfasis en las particularidades del sector, antes que uno convencional como el «asimilacionista» (Borello y Gonzáles, 2014). Desde esa perspectiva habría que concebir a las ICC no como una economía industrial típica sino como una emergente, donde el valor simbólico y económico es generado, tanto a nivel de la producción como de la demanda, dentro de redes sociales, esto es, a través de la interacción de múltiples agentes (Potts et al., 2008).

A pesar que el término parezca decir lo contrario, las ICC no operan ni con las líneas de montaje ni con las estrategias de estandarización o los patrones de consumo de los clásicos productos industriales, inscritos en mercados estables y ma- 
duros. Como lo señala el antropólogo Renato Ortiz, «reducir Hollywood a una línea de montaje es utilizar una figura retóri$\mathrm{ca}$, inadecuada para describir el funcionamiento de la industria cinematográfica» (Ortiz, 1996: 122). Asimismo, los productos culturales, aunque busquen alcanzar grandes cuotas de mercado, siempre se dirigen a públicos específicos, nunca a «masas». De allí que la cultura y comunicación de «masas» sean nociones de «poco provecho analítico» (Ortiz, 1996: 125).

Los alcances de esta realidad para los procesos de innovación son muy importantes. La innovación en los eslabones funcionales son menos determinantes para el éxito comercial de un producto cultural, la innovación vía $\mathrm{I}+\mathrm{D}$ tienen escasa influencia y la relevancia de la «innovación blanda» tiene una presencia alta, en contraste con lo que sucede en otras industrias (Nesta, 2009; Borello y Gonzáles, 2014). Por esa razón, no resulta pertinente utilizar los indicadores estándar para medir el desempeño en la innovación como el de las patentes. En las ICC son más centrales otros tipos de régimen de propiedad intelectual (Power, 2011).

La «innovación blanda» (soft innovation) puede entenderse como la «innovación en bienes y servicios que afecta principalmente la percepción sensorial, el atractivo estético o el atractivo intelectual en lugar del rendimiento funcional» (Nesta, 2009: 21). En ese sentido, cambios significativos en la forma de un prenda de ropa, en la composición de una canción o en el guión de una miniserie resultan claves para la expansión de su consumo, antes que la adopción de una nueva tecnología de distribución. De allí que no todos los productos comercializados bajo una misma tecnología, como el de las series en streaming, consiguen tener el mismo impacto.

Otros autores, incluyen dentro de la innovación blanda, además de los estéticos, a aquellos cambios (de eficiencia, sus- 
tantivos o disruptivos) en procesos organizacionales, modelos de negocio, experiencia del cliente, marketing y desarrollo de audiencias (Rodríguez, 2016: 25). A su vez, existe literatura que destaca antes que todo la capacidad del sector cultural y creativo para estimular nuevas ideas en otros sectores de la economía. En ese sentido, la innovación en las ICC se caracterizaría por ser un generador de conocimientos que influyen en la evolución del sistema económico (Potts, 2009). Al respecto, en el Perú, René Castro y Martha Tostes encontraron que la aglomeración de ICC tienen una gran capacidad de producir «derrames de conocimiento» en la demanda laboral inducida por la diversificación productiva o innovación tecnológica (Castro y Tostes, 2018).

Servicios de extensionismo tecnológico: de la manufactura a la cultura

La experiencia internacional en el campo del extensionismo tecnológico es muy heterogénea. No existe una única receta en la priorización de objetivos, cadena de valor o servicios. En la manufactura, la industria donde se originaron este tipo de debates, las prácticas exitosas en América Latina sugieren que los retos del extensionismo abarquen la productividad, la innovación, la exportación y la integración de la cadena de suministro. También, la experiencia recomienda que ello se realice a través de una combinación de servicios de aceleración tecnológica (adopción de tecnologías, transferencia tecnológica o acceso a laboratorios), financiamiento (vales para innovación, préstamos para ampliar el negocio o fondos para capacitación), asistencia técnica (en capacidades para la producción o asistencia en estándares) y conexión de las pymes (facilitación de la asociatividad o auspicio de eventos de buenas prácticas) (Andes et al., 2013: 23-27; Reig y Noeck, 2015). 
Para el caso de las industrias culturales y creativas, la experiencia internacional indica que los servicios de extensionismo pueden abarcar todos los eslabones desde la creación hasta el desarrollo de públicos, pasando por la producción, la comercialización y la internacionalización. Aparte del desarrollo de capacidades, la generación de información, el apoyo a las exportaciones, el extensionismo tecnológico es implementado mediante mecanismos de financiamiento. CORFO de Chile, por ejemplo, mediante el mecanismo de fondos concursables, ofrece anualmente recursos a proyectos audiovisuales para la producción o distribución de películas, series de televisión, videojuegos, documentales y largos de animación.

Los entrevistados en el estudio realizado no priorizaron a la creación en su demanda por servicios de extensionismo. Se insistió, más bien, que una de las fortalezas de las industrias culturales y creativas peruanas era el talento de los creadores y la amplia diversidad de tradiciones culturales. Tampoco se hizo mención a la «innovación blanda». El término, y en general las discusiones sobre la innovación en las ICC, aún es una problemática ajena a la gestión de empresas culturales en el Perú. La percepción de los trabajadores culturales consultados estuvo, más bien, enfocada en la necesidad de desarrollar sus procesos estrictamente comerciales y productivos: planificación empresarial, construcción de marcas, técnicas de producción, acceso a insumos y tecnologías y gestión de derechos de autor.

Teniéndolo en cuenta, así como atendiendo la experiencia internacional y las funciones que de la organización que encargó el estudio (el Instituto Tecnológico del Perú), a continuación se sugieren cinco tipos de servicios de extensionismo tecnológico que resulta importante impulsar a favor de las industrias culturales y creativas de economías emergentes como la peruana. 


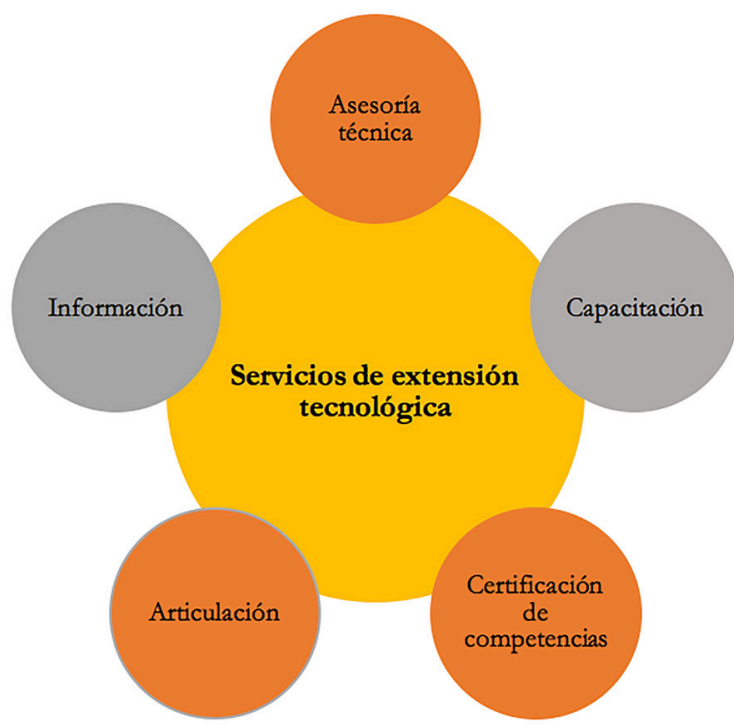

Figura 2: Lista de servicios de extensionismo para las industrias culturas y creativas.

\section{Servicios de asesoría}

La asesoría es un tipo de extensionismo personalizado. Resulta relevante implementarla debido a las gran variedad de perfiles de las empresas culturales y creativas por su origen sectorial y geográfico. También debido a las diferentes fases de desarrollo de cada una.

La asesoría podría darse a través de clínicas y mentorías. Las clínicas tienden a ofrecer herramientas y criterios de acción a los proyectos empresariales de acuerdo a sus necesidades, con el fin de conseguir mejorar su organización, planificación y crecimiento. Normalmente las dan especialistas en distintas área, específicas como el diseño gráfico o generales como la gestión cultural. En el Perú, esa modalidad ha sido implementada en el Encuentro Conecta del Ministerio de Cultura. 
Las mentorías, por su lado, tienen un origen anglosajón. Son procesos de retroalimentación ofrecidos con base en la experiencia del mentor para que el beneficiario amplíe sus conocimientos técnicos. El mentor puede ser un especialista pero también un empresario, creador o gestor cultural con experiencia en el tema que requiera asesoramiento. Como las clínicas, las mentorías dan respuestas a problemas específicos. Pueden formar parte de un programa con otro tipo de servicios de extensionismo: aceleradores de negocios culturales como El Pauer de Medellín o laboratorios de empresas como la Red de Industrias Creativas de España.

En el grupo focal realizado con productores audiovisuales de Piura, región del extremo norte, fue sugerida una mentoría en procesos de realización de vídeos, tal como se indica en la caracterización de la demanda. «Las personas que tienen más experiencia nos pueden nutrir», comenta Aron Loayza de Ángel Films. También se propuso que la mentoría podría tener un formato tipo pasantía donde se le da la oportunidad al beneficiario de participar en la grabación del vídeo de un productor reconocido con el fin de extraer lecciones desde la práctica.

\section{Servicios de capacitación}

Las capacitaciones generan procesos de aprendizaje especializado. Pueden darse a través de cursos o talleres. Los primeros, a diferencia de los segundos, ofrecen la ventaja de poder ser más extensos y de encadenar unidades temáticas. Los talleres son capacitaciones específicas, aisladas e inminentemente prácticas. Normalmente los programas de formación los combinan, tal lo hace Piso 16-Laboratorio de iniciativas culturales UNAM. Lo importante es que la oferta de conocimientos esté ajustada a las necesidades de los productores culturales y creativos. 
TABLA 1. Lista materias sugeridas por los entrevistados para los servicios de capacitación según eslabón de la cadena de valor.

\begin{tabular}{|c|c|}
\hline $\begin{array}{c}\text { Eslabón de la cadena } \\
\text { de valor }\end{array}$ & Materia \\
\hline Producción & $\begin{array}{l}\text { Elaboración de planes de negocio } \\
\text { Gestión de derechos de autor } \\
\text { Técnicas de tejido } \\
\text { Diseño y desarrollo de marcas de moda } \\
\text { Realización audiovisual } \\
\text { Planificación del pipeline en animación } \\
\text { Acceso y gestión de almacenamiento de los produc- } \\
\text { tos audiovisuales } \\
\text { Técnicas de rigging en animación } \\
\text { Blockechain para la gestión de derechos de autor }\end{array}$ \\
\hline Comercialización & $\begin{array}{l}\text { Estrategias de comercialización } \\
\text { Estándares y requisitos de comercialización de ser- } \\
\text { vicios en streaming como Netflix } \\
\text { Marketing cultural } \\
\text { Estrategias de marketing digital } \\
\text { Monetización de YouTube } \\
\text { Estrategias de distribución digital de la música }\end{array}$ \\
\hline Internacionalización & $\begin{array}{l}\text { Elaboración de portafolios para la participación en } \\
\text { festivales y mercados. } \\
\text { Estrategias de participación en mercados y festiva- } \\
\text { les }\end{array}$ \\
\hline Desarrollo de públicos & Estrategias de desarrollo de públicos \\
\hline
\end{tabular}

Además de adecuar los contenidos de los SET a los públicos, deben priorizarse algunos temas que a nivel internacional vienen siendo claves para el desarrollo de las industrias culturales y creativas: la inteligencia artificial aplicada a la creación y el conocimiento de los consumidores, la cocreación con los consumido- 
res por medio de tecnologías de la información y comunicación, y el desarrollo de públicos.

A la vez, también es importante que se tomen en cuenta, para poder extender su conocimiento, los factores de cambio en las ICC, insertas en procesos de convergencia 3.0. En su informe del 2018 sobre las perspectivas en la industria del entretenimiento y los medios, la consultara PricewaterhouseCoopers (PwC) señala que esos factores son la conectividad ubicua, el consumo de teléfonos celulares, la necesidad de buscar nuevas fuentes de crecimiento, las plataformas digitales y la personalización del consumo (PWC 2018: 6). También es importante tener en los planes de cualquier centro de extensionismo, u organización afín, a las ocho tecnologías que, según PwC, motivarán en los próximos años procesos de innovación: robots, internet de las cosas, realidad aumentada, realidad virtual, drones, 3D, inteligencia artificial y blockechain (PwC, 2018:19).

\section{Articulación intersectorial}

Las fallas de coordinación en el mercado son comunes. Para corregirlas, los Estados pueden desarrollar procesos de articulación que permitan fortalecer los vínculos entre los diferentes agentes de los ecosistemas económicos. Para impulsar las industrias culturales y creativas, esa articulación podría hacerse a tres niveles: a) la articulación entre empresas y sectores culturales; b) la articulación entre empresas y universidades y centros educativos; c) la articulación entre empresas y las distintas entidades públicas dedicadas a la promoción de las industrias culturales y creativas.

El primer tipo de articulación permite mejorar las relaciones entre los agentes involucrados en las distintos eslabones de la cadena valor, así como generar espacios de coordinación entre los diferentes segmentos de las ICC o de estos con otros sec- 
tores económicos. El Programa de innovación en las industrias creativas de la Agencia Nacional de Investigación e Innovación (ANII) de Uruguay, por ejemplo, consiste en la

cofinanciación de proyectos con fondos no reembolsables a empresas de cualquier sector económico con la finalidad de que usen los servicios de empresas culturales y creativas (diseño, música, audiovisual, etc.). Entre sus resultados está el desarrollo de un programa de realidad virtual para reducir el estrés de los niños antes de las cirugías del Instituto de Cardiología Integral. Con instrumentos como éste, conocidos como voucher, se consigue desarrollar «vínculos entre los actores que participan en la economía creativa». ${ }^{2}$ (Benavente y Grazzi, 2017: 35)

Con el segundo tipo de articulación puede incentivarse la difusión de los conocimientos y tecnologías generadas por las universidades, promover el diseño de proyectos de transferencia de conocimientos y vincular la agenda académica de investigación con las necesidades de las empresas culturales. Esta fue la línea programática seguida por InnoUAM_IndustriasCulturales, jornada sobre las innovaciones, tecnologías y modernización de las industrias culturales y creativas, organizada por el 2021 por el Vicerrectorado de Innovación, Transferencia y Tecnología de la Universidad Autónoma de Madrid. Con el apoyo de la Comunidad de Madrid, allí se presentaron resultados de los investigadores de la UAM, productos y servicios en desarrollo en el sector empresarial, así como exposiciones de inversionistas relacionados a las industrias culturales y creativas ${ }^{3}$.

Con el tercer tipo de articulación, finalmente, habría mayores capacidades tanto para formular leyes, políticas o planes que mejoren la regulación del mercado de las ICC como para

$2 \mathrm{Al}$ respecto, ver: https://creativas.anii.org.uy.

$3 \mathrm{Al}$ respecto, ver: https://eventos.uam.es/57902/detail/innouam_industriasculturales.html.

Alfaro Rotondo , Santiago (2021). «Servicios de extensionismo tecnológico para el desarrollo de las industrias culturales y creativas». Monograma. Revista Iberoamericana de Cultura y Pensamiento, n. ${ }^{\circ} 9$, pp. 155-186. doi: 10.36008/monograma.2021.09.2105. http: revistamonograma.com. ISSN: 2603-5839. 
implementar de manera coordinada programas a favor de las empresas culturales y creativas. El Consejo de Industrias Creativas (Creative Industries Counci) cumple ese rol en el Reino Unido. El Consejo está integrado por líderes de la industria creativa y digital (televisión, videojuegos, moda, música, arte, publicidad y cine) y tiene como misión principal ser una bisagra entre el gobierno y el sector creativo con el fin de reducir los obstáculos para su crecimiento relacionados al acceso a financiamiento, los mercados de exportación o la propiedad intelectual ${ }^{4}$.

\section{Servicios de información}

La profesionalización de la gestión de empresas culturales demanda de información. Producir información permite obtener evidencia para tomar decisiones ajustadas a realidades, no a ideas, intuiciones o impulsos personales. Uno de los mayores aportes de un centro de extensionismo para las ICC sería el de incentivar la producción de información y conocimiento que permita a las micro, pequeñas y medianas empresas mejorar sus procesos de producción, comercialización, internacionalización y desarrollo de públicos. Los entrevistados lo reconocieron. Laerke Skyum, directora de la empresa de diseño de modas Ayni, recuerda, por ejemplo, que «hay muy poca información y estadísticas sobre las empresas (de diseño de modas)».

$\mathrm{Al}$ respecto, el proyecto Espectro de audiencia (Audience Spectrum), servicio público del Reino Unido ofrecido a todos las organizaciones culturales británicas, es un referente para tomar en cuenta. El servicio es una base de datos accesible por medio de la cual puede segmentarse a toda la población de ese país a través de diferentes variables como las actitudes hacia la cultura, el perfil sociodemográfico u otras. Las segmentaciones permi-

$4 \mathrm{Al}$ respecto, ver: https://www.thecreativeindustries.co.uk/about-us. 
ten a las organizaciones saber quiénes viven cerca de su área de influencia y qué perfiles tienen. Con base en ello pueden identificar la composición de sus públicos.

El Espectro de audiencia es gestionado por la Agencia de Audiencia (Audience Agency), institución que ofrece otros servicios más vinculados al desarrollo de públicos como reportes, herramientas metodológicas, estadísticas y guías para diseñar planes de desarrollo de públicos. La Agencia de Audiencia busca «permitir que las organizaciones culturales utilicen nuestros datos nacionales para aumentar su relevancia, alcance y resiliencia» ${ }^{5}$. En el Perú y otros países de América Latina existe una brecha entre la información disponible y su uso que podría ser cerrada a través de servicios de extensionismo similares.

\section{Certificación de competencias laborales}

Por último, un quinto servicio de extensionismo tecnológico requerido según la demanda existente es la certificación de competencias laborales. Según el Ministerio de Trabajo y Promoción del Empleo de Perú, este tipo de certificación permite «emitir un certificado de competencia laboral a las personas que muestran un desempeño óptimo y satisfactorio en la evaluación y garantizan la calidad de su desempeño laboral» ${ }^{6}$.

En las industrias culturales y creativas existen muchos oficios, tradicionales o no, que son ejecutados por personas en base solo a su experiencia o el conocimiento adquirido por medio de procesos educativos informales. Ese es el caso de los artesanos textiles o de los técnicos de teatro (tramoyistas, luminotécnicos, etc.). Los primeros aplican técnicas que han sido transmitidas de generación en generación. Los segundos han ido aprendiendo

$5 \mathrm{Al}$ respecto, ver: www.theaudienceagency.org. $6 \mathrm{Al}$ respecto, ver: https://www.gob.pe/mtpe. 
el oficio en la práctica y no tiene la posibilidad certificar sus conocimientos porque no existe en la oferta educativa una especialidad como la suya. Por casos como estos, la certificación permitiría generar mayores incentivos a los trabajadores y, a la vez, contribuir a la formación de un mercado laboral formal.

El Servicio Nacional de Aprendizaje (SENA) de Colombia lo entiende así. Por eso cuenta con centros de formación distribuidos en todo el país donde se ofrece formación profesional (titulada y complementaria) en algunas actividades vinculadas a las industrias culturales y creativas. A la vez, el SENA también desarrolla el proceso de Evaluación y Certificación por Competencias Laborales que permitió que en el 2018 sean entregadas 1356 certificaciones laborales en temas vinculados a la llamada «economía naranja» ${ }^{7}$. Un centro de extensionismo tecnológico podría, entonces, asumir funciones similares o promover que la incorporen organizaciones privadas.

\section{Criterios para la implementación de SET para las ICC}

Los cinco servicios indicados requieren adaptarse a la realidad del países donde sean implementados, claro está. Más allá de los contextos, sin embargo, se sugiere considerar los siguientes criterios de acción, mencionados por los informantes del estudio y/o la literatura analizada.

\section{Coordinación con el órgano rector en política cultural}

El extensionismo tecnológico es un tipo de política industrial, no cultural. Sin embargo, las industrias culturales y creativas (ICC) forman parte del sector cultura, por lo que se sugiere mantener coordinaciones con el órgano rector en la materia

$7 \mathrm{Al}$ respecto, ver: https://sena.edu.co/es-co/Noticias/Paginas/noticia.aspx?IdNoticia $=3559$. 
durante el diseño, la ejecución y evaluación de los servicios de extensionismo tecnológico (SET). Ello contribuirá a establecer políticas articuladas. Pablo Roselló, director regional de Artes para las Américas del British Council, hizo una sugerencia en la misma dirección, teniendo en cuenta la experiencia del Reino Unido: «Es importante que el Ministerio de la Producción tenga en cuenta que la promoción de las ICC no debe ser ajena al Ministerio de Cultura. La agenda económica no debe estar desconectada de la política cultural».

Reconocimiento del carácter dual de los bienes y servicios de las ICC

La historia de la evolución conceptual de las ICC es el de la tensión entre economía y cultura, comercio y libertad creativa. La misma tensión se expresa en la evolución de las políticas públicas: algunas priorizan el valor cultural y otro el económico de las ICC. Sin embargo, tal como lo señala David Throsby, «si nos tomamos en serio el intento de conseguir una teoría - económica - completa, y en última instancia con validez operativa en la toma de decisiones, es esencial que el valor cultural se admita junto con el valor económico en la consideración del valor total de los bienes y servicios culturales» (Throsby, 2008: 56).

Las ICC generan, en su actividad comercial o social, ambos tipos de valores que son irreductibles uno de otro. En consecuencia, aunque el interés de una política de extensionismo tecnológico solo tenga objetivos económicos, no debe dejar de considerar esta condición. El valor cultural puede ser transformado o valorizado en términos económicos, con base en las llamadas metodologías de valorización contingente. Además, el valor intrínseco de la cultura produce externalidades positivas y beneficios sociales cuyo conocimiento y promoción contribuye al desarrollo económico. 


\section{Adopción de un modelo «demarcatorio» en la promoción} de la innovación

En el campo de las ICC, la promoción de la innovación, una de los componentes centrales de los servicios de extensionismo tecnológico (SET), no puede realizarse sin reconocer sus particularidades. Su naturaleza no es igual a la de los bienes y servicios de la industria de manufactura, tal como lo demuestra la centralidad de la creatividad en la producción y la aleatoriedad de la demanda. En consecuencia ni las políticas de innovación de los servicios de extensionismo ni los indicadores dedicados a medir su éxito pueden ser los mismos que los usados en la promoción de la cadena de valor de otras industrias.

La innovación preponderante en las IIC es «blanda», esto es, se vincula con cambios en «procesos, estructuras organizacionales, modelos de gestión, percepción sonora, experiencia personalizada, diferenciación de productos y servicios, marketing o modelos de negocio»; antes que por la transformación de procesos industriales o tecnológicos (Rodríguez 2016: 30). Los servicios propuestos, entonces, deben tener como orientación la búsqueda de la innovación blanda en toda la cadena de valor de las industrias culturales y creativas, incluyendo la creación. Eso demanda que sus beneficiarios no solo sean empresarios sino también artistas y creativos, más allá que los últimos no hayan priorizado la creatividad como una capacidad a ser desarrollada.

Incorporación del desarrollo de públicos como objeto y enfoque de los servicios de extensionismo

Una de las particularidades del comercio cultural y creativo es el protagonismo de los públicos en la cadena de valor. Para alcanzar sus objetivos, las organizaciones culturales requieren desarrollar conexiones significativas y relaciones sostenibles con ellos. No obstante, la tendencia no ha tenido ese dirección. La 
gestión cultural ha sido ofertacéntrica cuando el público debe estar en el centro de las organizaciones para conseguir impactos sociales, económicos y simbólicos. Es decir, empresarios, creadores y gestores culturales han tendido a preocuparse más por los contenidos que ofrecen que por comprender y relacionarse con quienes los consumen o se apropian de ellos.

Lo cierto es que toda oferta cultural tiene siempre públicos específicos. Nunca el público es general. El desarrollo de públicos es un enfoque emergente en la gestión y política cultural que busca conseguir que las organizaciones y proyectos culturales identifiquen esos públicos específicos, comprendan su comportamiento y diseñen objetivos, estrategias y acciones para fortalecer y diversificar sus relaciones con ellos, con base en los recursos presupuestales y humanos con los que cuentan.

La urgencia de promover el enfoque es aún mayor en el contexto de la expansión de las tecnologías digitales, ya que han incrementado la relevancia de los públicos en el ecosistema de las ICC. Actualmente intervienen de manera crítica en la propagación y la creación de contenidos. La división entre productores y consumidores viene siendo alterada por el cambio digital. Por ese motivo, el protagonismo de los públicos o consumidores en los procesos productivos es uno de los temas de mayor debate a nivel internacional. De hecho, algunos afirman que la cocreación, la generación de actividades conjuntas entre productores y consumidores, es el «nuevo estándar de la innovación» en el mercado (Huijbers, 2017; Czarnota, 2018). El impulso de servicios de extensionismo tecnológico no puede dejar de tenerlo en cuenta.

\section{Apuesta por las economias de nicho}

En el campo de las políticas industriales suele priorizarse la promoción de economías de amplios mercados. En las ICC, 
sin embargo, las economías de nicho no solo son importantes porque garantizan la sostenibilidad de la diversidad cultural sino también porque han adquirido un valor económico mayor en el contexto de la expansión de las tecnologías digitales. Según la teoría de la Larga cola, la disminución de los costos de producción y distribución generadas por internet permite ahora que los bienes y servicios con un público muy específico puedan ser tan atractivos como los de consumo masivo (Anderson, 2007). El éxito de empresas como Amazon o Netflix, con catálogos extensos, según los promotores de la teoría, muestran las posibilidades de sacar beneficios de la «larga cola» de productos de demanda minoritaria.

Los entrevistados indicaron algo parecido. Según las diseñadoras de moda consultadas, el Perú puede ser competitivo en el mercado internacional en mercados muy específicos donde sea valorada la sostenibilidad y la innovación, no en el comercio al por menor (retail) donde el protagonismo lo tienen China y la India. Antes que apostar por la venta de productos al por menor a bajos precios, la oportunidad está, desde esa perspectiva, en dominar segmentos de mercado de alta capacidad adquisitiva que valoren fibras como la alpaca y/o el comercio justo. Con el fin de que no se pierdan oportunidades de desarrollo económico, los servicios de extensionismo deben tener presente estas teorías y opiniones.

\section{Poner en el centro las desigualdades}

Las políticas industriales, como los SET, están orientadas a promover el crecimiento económico a través del aumento de la productividad de las empresas. Para conseguirlo con sostenibilidad y equidad, resulta necesario acompañar las medidas de promoción empresarial con otras que corrijan las desigualdades que se manifiestan en las ICC. 
Una extensa literatura da cuenta de la existencia de exclusiones, asimetrías y subrepresentaciones de poblaciones en la producción, circulación y consumo de bienes, servicios y actividades culturales; según género, clase social, etnicidad, generación, discapacidad y orientación sexual (O’Brien y Oakley, 2015). Ello sucede tanto en el Sur global como en el Norte Global, en la música como en la literatura o el cine. La tendencia general es que los hombres blancos, heterosexuales, de niveles socioeconómicos altos o medios y sin restricciones en sus capacidades, normalmente poseen mayores oportunidades e influencia en la fuerza de trabajo, las representaciones y la demanda cultural; lo que expresa la influencia de las disparidades existentes en la sociedad, no solo en el sector cultural. «La cultura refleja las inequidades, las inequidades reflejan la cultura», como dicen Orian Brook, Dave O’Brien y Mark Tylor (2020).

Para atender esta realidad, los servicios de extensionismo tecnológico requieren contemplar las condiciones de producción y consumo cultural y preocuparse por el impacto de la cultura en las inequidades sociales. Ese es el enfoque que posee el Centro de Evidencia y Políticas de Industrias Creativas (PEC) del Reino Unido, impulsado por Nesta, fundación para la innovación, y un consorcio de universidades. Las investigaciones que realizan para identificar los límites a la diversidad, las brechas de talento, barreras para el comercio y el crecimiento local de las industrias creativas toman en cuentas las inequidades de la cultura.

Una de esos estudios, por ejemplo, da cuenta que el $61 \%$ de los trabajadores de la industria audiovisual provienen de familias privilegiadas, lo que la hace uno de los sectores más elitistas de las industrias creativas y la economía británica en su conjunto (Heather, O’Brien y Gable, 2021). Por evidencia como la indicada, la Red de Mentoría Creativa (Creative Mentor Networking), también del Reino Unido, busca hacer del mundo creativo uno 
más inclusivo por lo que ofrece programas de mentoría, capacitaciones y asesoría a pequeños negocios para incrementar la participación de personas de niveles socioeconómicos bajos en la fuerza laboral de las industrias creativas. La corrección de desigualdades garantiza derechos ciudadanos, así como mercados prósperos y sostenibles.

\section{Conclusiones}

La información cualitativa obtenida en el estudio realizado por encargo del Instituto Tecnológico de la Producción indica que en la música, el diseño de moda y la industria audiovisual (cine, videojuegos y animación) peruana existe una reducida oferta de servicios de extensionismo tecnológico (SET). La ausencia de apoyo especializado ha sido compensada con la «intuición». Esta palabra u otras que contienen ideas parecidas son las más mencionadas por los entrevistados: «se hace camino al andar», «todo ha sido intuitivo», «aprendimos haciendo», «nos capacitamos autodidácticamente». Un testimonio ejemplifica esta tendencia a partir de la experiencia de comercialización de productos audiovisuales:

Hemos tenido que aprender sobre los números a partir de nuestra propia experiencia. Ponte, que día funcionaba mejor lanzar el vídeo, qué días teníamos más clicks, cuándo segmentar o no la página con los avisos. No sabíamos tampoco cómo monetizar esta información para llegar a los clientes. Nuestra lucha constante para conseguir auspiciadores ha sido saber cómo convencerlos que nuestro producto podía serles beneficioso. ${ }^{8}$

La labor empresarial es, por lo tanto, básicamente autodidacta o dependiente de las capacidades personales de sus directivos.

8 Representante de empresa del sector audiovisual. 
Para ampliar la oferta de SET con el fin de cambiar una realidad como esta resulta necesario reconocer las particularidades de los negocios culturales y creativos. Dos principalmente: la centralidad de la creatividad en los procesos productivos y la aleatoriedad de la demanda. También pasa por promover una diversidad de servicios, entre los que están la asesoría técnica (clínicas, mentorías), las capacitaciones (cursos, talleres), la generación de información (reportes, difusión de bases de datos) y la articulación (vinculación con la academia, coordinación entre entidades públicas y encadenamiento de la cadena de valor).

Para potenciar sus impactos, todos estos servicios requieren ser implementados mediante la coordinación con los órganos rectores en materia de política cultural, el reconocimiento del carácter dual de los bienes y servicios de las ICC, la adopción de un modelo «demarcatorio» en la promoción de la innovación, la apuesta por los mercados de nicho, la priorización de medidas que corrijan las desigualdades y la promoción del desarrollo de públicos como enfoque central para la gestión y política cultural.

La incorporación de procedimientos, técnicas y conocimientos nuevos en los procesos productivos de las industrias culturales y creativas es prioritario para su desarrollo, especialmente en el contexto de la Emergencia Sanitaria actual. Ello no es tarea solo de las políticas culturales sino también de las políticas industriales. Sin embargo, estas no pueden ser implementadas sin atender las naturaleza excepcional de los procesos de producción, circulación y consumo de los bienes, servicios y actividades culturales. 


\section{REFERENCIAS BIBLIOGRÁFICAS}

Anderson, C. (2007). La economía Long Tail: de los mercados de masas al triunfo de lo minoritario. Barcelona: Tendencias.

Andes, S., Ezell, S. y Leal, J. (2013). An Alternative to Mercantilism: Manufacturing Extension Services in Latin American and Caribbean Countries. Washington, D. C.: The Information Technology and Innovation Foundation (ITIF).

Benavente, J. M. y Grazzi, M. (2017). Políticas públicas para la creatividad y la innovación: impulsando la economía naranja en América Latina y el Caribe. Washington, D. C.: BID.

Borello, J. y GonzÁlez, L. (2014). «Innovación en las industrias culturales y creativas ¿Cómo caracterizarla y medirla? El caso de la producción audiovisual en los países semiindustrializados». En Azcúa, R., Roitter, S., Bacic, M., Erbes, A. y Aggio, C. (eds.). Innovación, desarrollo y conducta innovativa de las Pymes. Brasil: Red Pymes.

Brook, O., O'Brien, D. y TAYlor, M. (2020). Culture is bad for you. Inequality in the cultural and creative industries. Glasgow: Manchester University Press.

Campbell, P., O’Brien, D. y Taylor, M. (2018). «Cultural Engagement and the Economic Performance of the Cultural and Creative Industries: An Occupational Critique». Sociology, vol. 53(2), pp. 347-367.

Convenio Andrés Bello (2009). Cuenta satélite de cultura. Manual metodológico para su implementación en Latinoamérica. Bogotá: Convenio Andrés Bello.

Czarnota, J. (2018). Co-creation, innovation and new service development: the case of the videogames industry. Nueva York: Routledge.

Garnham, N. (2011). «De las industrias culturales a las creativas. Análisis de las implicancias en el Reino Unido». 
En Bustamante, E. (ed.). Industrias creativas. Amenazas sobre la cultura digital. Barcelona: Gedisa.

Heather, C., O’Brien, D. y Gable, O. (2021). Screened out. Tackling class unequality in the UK Screen Industries. Londres: Creative Industries Policy and Evidence Centre.

HuijBers, P. (4 de Octubre de 2017). Innovation, Digital Co-creation is the New Standard for. Disponible en: https://blog.global.fujitsu.com/fgb (consultado el 14 de mayo de 2021).

Jenkins, H., Ford, S. y Green, J. (2015). Cultura Transmedia. La creación de contenido y valor en una cultura en red. Barcelona: Gedisa.

Mangematin, V., Sapsed, J. y Schüssler, E. (2014). «Disassembly and reassembly: An introduction to the Special Issue on digital technology and creative industries». Technological Forecasting \& Social Change.

Miège, B. (2011) «Theorizing the Cultural Industries: Persistent Specificities and Reconsiderations». En Wasko, J., Murdock, G. y SousA, H. (eds.). The Handbook of the Political Economy of Communications. Oxford: Blackwell Publishing.

Navarro, J. C., Benavente, J. M. y Crespi, G. (2016). The new imperative of innovation: policy perspectives for Latin America and the Caribbean. Washington, D. C.: BID.

Nesta (2009). Soft innovation. Towards a more complete picture of innovative change. Londres: Nesta.

O'Brien, D. y OAKLey, K. (2015). Cultural Value and Inequality: A Critical Literature Review. Arts and Humanities Research Council's Cultural Value Project. Wiltshire: Arts and Humanities Research Council.

OrTiz, R. (1996). Otro territorio. Ensayos sobre el mundo contemporáneo. Buenos Aires: Universidad Nacional de Quilmes.

Potts, J., Cunningham, S. y Hartley, J. (2008). «Social Network Markets: A New Definition of the Creative Industries». Journal of Cultural Economics, 32(3), pp. 167-85. 
PotTs, J. y Morrison, K. (2009). Nudging Innovation Fifth Generation Innovation, Behavioural Constraints, and the Role of Creative Business: Considerations for the Nesta Innovation Vouchers Pilot. Londres: Nesta.

Power, D. (2011). The European Cluster Observatory. Priority Sector Report: Creative and Cultural Industries. Luxemburgo: Unión Europea.

PwC-PricewaterhouseCoopers (2018). Perspectives from the Global Entertainment \& Media Outlook 2018-2022. Trending now: convergence, connections and trust. Retrieved. Disponible en: https://www.pwc.com/gx/en/entertainment-media/outlook/ perspectives-from-the-global-entertainment-and-media-outlook-2018-2022.pdf.

Rama, C. (2003). Economía de las industrias culturales en la globalización digital. Buenos Aires: Eudeba.

ReIG, N. y Noeck, M. (2015). Extensionismo Industrial e innovación. El rol del Centro de Extensionismo Industrial en Uruguay. Montevideo: Centro de Extensionismo Industrial.

Richeri, G. (2011). «Ambigüedades desde la economía. Las debilidades de la creatividad». En Bustamante, E. (ed.). Industrias creativas. Amenazas sobre la cultura digital. Barcelona: Gedisa.

Rodríguez, J. (2016). To Sell or Not To Sell? An Introduction to Business Models (Innovation) for Arts and Culture Organisations. Bruselas: IETM-International Network for Contemporary Performing Arts.

Rosen, S. (1981). «The economics of superstars». The American Economic Review, 71(5), pp. 845-858.

Shapira, P., Youtie, J., Cox, D., Yuarra, E., Abdullah, G., Rogers, J. y Downing, C. (2015). Institutions for Technology Diffusion. Inter-American Development Bank. Disponible en: https:/ / publications.iadb.org/publications/english/document/Institutions-for-Technology-Diffusion.pdf. 
SIERRA, P. (2010). Centros de extensionismo: aspectos a considerar para el logro de sus objetivos. Bogotá: COLCIENCIAS.

Stigler, G. y Becker, G. (1977). «De Gustibus Non Est Disputandum». The American Economic Review, pp. 76-90.

Throsby, D. (2008). Economía y cultura. México D. F.: Consejo Nacional para la Cultura y las Artes.

Tolila, P. (2007). Economía y cultura. México D. F.: Consejo Nacional para la Cultura y las Artes.

Tostes, M. L. y Catro, R. I. (2018). «Innovación e industrias creativas y culturales en Perú. Evidencia empírica de los determinantes de la demanda laboral inducida por innovación». En Industrias culturales y economía creativa en Latinoamérica: Desarrollo económico y social en la región. Cali: Uniagustiniana, pp. 213-264.

Twose, R. (2016). A Future for the Creative Economy: a report by Ruth Towse. CREATe.

Unesco (2009). Marco de Estadísticas Culturales (MEC) de la Unesco 2009. París: Unesco.

YÚDICE, G. (2018). «The Challenges of the new media scene for public policies». En Durrer, V., Millet, T., O’Brien, D. (eds.). The Routledge Handbook of Global Cultural Policy. Nueva York: Routledge.

ZaLLO, R. (2007). «La economía de la cultura (y de la comunicación) como objeto de estudio». Zer: Revista de estudios de comunicación (22). 